\title{
0 impacto do motor flex no mercado brasileiro de motocicletas e na liderança da Honda
}

\author{
Diogo Signor* \\ Francis Carlo Petterini**
}

Recebido: 30/11/2016 Versão Revisada (entregue): 03/06/2017 Aprovado: 19/06/2017

RESUMO

Em 2009 a Honda incorporou o motor flex em parte de suas motocicletas, o que ocorreu sob um contexto peculiar, já que a empresa poderia ter sua liderança ameaçada por novos concorrentes e o mercado estava retraído. O artigo contextualiza e analisa o impacto da inovação, estimando por controle sintético que as vendas contrafactuais da Honda seriam até 27\% menores no quadriênio 2009-2012. Associado ao fato que a Honda ganhou cinco pontos percentuais em parcela de mercado, isso aponta a relevância da inovação para manter sua liderança.

Palavras-Chave | Mercado Brasileiro de Motocicletas; Motor Flex; Avaliação de Impacto; Controle Sintético.

Códigos-JEL | C32; L62; O33

* Universidade Federal de Santa Catarina (UFSC), Florianópolis (SC), Brasil. Email: diogosignor@gmail.com

** Universidade Federal de Santa Catarina (UFSC), Florianópolis (SC), Brasil. Email: f.petterini@ufsc.br 


\title{
The impact of the flex-fuel motor on the Brazilian motorcycle market and on the Honda leadership
}

\begin{abstract}
In 2009 Honda incorporated the flex-fuel engine in some of its motorcycles. This happened under a peculiar context, once the firm had its leadership threatened and the market was retracted. The article contextualizes and analyzes the impact of this innovation, estimating by synthetic control that the Honda's counterfactual sales would be $27 \%$ lower in the period 2009-2012. This and the fact that Honda gained five percentage points in market share indicate to the relevance of innovation to maintain its leadership.
\end{abstract}

KeYwords | Brazilian Motorcycle Market; Flex-Fuel Motor; Impact Evaluation; Synthetic Control.

JEL CODES | C32, L62, O33 


\section{Introdução}

A tecnologia flex denomina um sistema de geração de energia mecânica a partir da mistura de combustíveis armazenados em um mesmo tanque. No Brasil, a ideia do "veículo flex" surgiu na década de 1970 e se mostrou operacional nos anos 2000 com o advento de determinados equipamentos eletrônicos. Esse tipo de veículo pode ser abastecido com a combinação de gasolina/etanol que o consumidor preferir, dependendo de preços, potência e torque dados pela mistura, satisfação com questões ambientais, etc.

O lançamento comercial do primeiro veículo flex ocorreu em 2003, quando a Volkswagen incorporou essa motorização no Gol 1.6. Em 2009, quando a inovação já havia se difundido, $90 \%$ das vendas de automóveis novos foram de modelos bicombustíveis. DeSouza, Petterini e Miro (2010) estimam que os modelos que permaneceram monocombustível, entre 2004 e 2008, perderam cerca de 30\% das vendas por conta disso. Então a demanda pelo produto diferenciado poderia explicar a motivação e a velocidade da difusão, como em outros casos apresentados em Rogers e Olaguera (2003).

Nas motocicletas a inovação foi incorporada em 2009, quando a Honda lançou a CG 150 Mix em um contexto que é possível destacar quatro fatos. Primeiro, a Honda era (e é) a líder do mercado e a CG 150 era (e é) o modelo mais vendido. Segundo, a mídia especializada aponta que em 2007 esse projeto já seria operacional para a Honda e que a Kasinski, detentora da terceira maior parcela de mercado, atrás da Yamaha, estava testando um modelo flex. Terceiro, a economia brasileira sofreu uma forte retração em 2009 como reflexo da "crise dos subprimes", que afetou as vendas de motocicletas zero km. Quarto, só em 2013 a Yamaha incorporou o motor flex nos seus modelos, mesmo ano em que a Kasinski deixou o mercado sem nunca ter lançado um modelo flex. Assim, uma potencial conexão entre estes pontos seria que a incorporação do motor flex na CG 150, particularmente em 2009, pode ter sido útil para Honda mitigar perdas nas vendas e aumentar sua liderança.

Considerando essa hipótese, durante a revisão da literatura empírica da "economia da inovação", notaram-se uma riqueza de análises sobre os processos de inovação, inclusive sobre o motor flex, e uma escassez de análises ex-post, o que é enfatizado nos surveys de Cohen (2010) e Mairesse e Mohnen (2010). Entretanto, como argumentam estes autores, os estudos de impacto da inovação sobre indicadores de resultados das empresas seriam tão importantes quanto os estudos 
de processo (e.g., indicadores de P\&D e patentes), já que os impactos retroalimentariam os processos.

Além disso, durante essa revisão também se observou uma escassez de literatura sobre o mercado brasileiro de motocicletas, havendo uma concentração de estudos na relação das motocicletas com a mobilidade urbana (SERAPHIM, 2003), com acidentes de trânsito (VASCONCELLOS, 2008) e a qualidade do ar (ANDERSON, 2009). No entanto, as motocicletas representam cerca de $1 / 4$ da frota nacional de veículos e seu mercado possui uma série de peculiaridades: uma empresa líder que também atua no mercado de automóveis; um crescimento extraordinário nos últimos anos; uma relação intrínseca com sistemas de consórcio; e um conjunto de informações passível de tabulação e pouco explorado em trabalhos acadêmicos.

Assim, a proposta desse artigo é apresentar um exercício de teste da hipótese de que a incorporação do motor flex pela Honda lhe foi útil para mitigar perdas nas vendas e aumentar sua liderança no período 2009-2012, entre a retração do mercado com a "crise dos subprimes" e a incorporação da motorização pela Yahama. Consequentemente, o artigo contribui com a análise ex-post de um caso brasileiro de inovação, além de promover uma discussão sobre o mercado de motocicletas.

Para cumprir com esse propósito, exploraram-se os dados de vendas no atacado compilados pela Associação Brasileira dos Fabricantes de Motocicletas, Ciclomotores, Motonetas, Bicicletas e Similares (Abraciclo). No entanto, as peculiaridades da estrutura de informações inviabilizam o uso de técnicas mais tradicionais como os modelos baseados em escolhas dos agentes (DESOUZA; PETTERINI; MIRO, 2010) ou muitos dos modelos baseados no arcabouço de Neyman-Rubin (IMBENS; WOOLDRIDGE, 2009). Alternativamente, notou-se a possibilidade de executar um estudo comparativo por "controle sintético", como em Abadie, Diamond e Hainmueller $(2010,2015)$, o que também configura uma contribuição do artigo para a literatura nacional.

Embora o controle sintético não permita o entendimento dos "efeitos substituição" entre modelos, os resultados indicam que, se Honda não tivesse incorporado o motor flex, suas vendas poderiam ter sido $17 \%$ ou $27 \%$ menores no quadriênio 2009-2012. Em associação ao fato de que a Honda ganhou cinco pontos percentuais em parcela de mercado nesse período, tais resultados corroboram a conjectura de que a inovação da motocicleta flex foi relevante para a Honda mitigar perdas nas vendas e aumentar sua liderança na fase pós "crise dos subprimes".

A seguir se discorre sobre o mercado brasileiro de motocicletas. Posteriormente abordam-se as perspectivas da análise proposta e metodologia do controle sintético, 
bem como os desafios encontrados na base de dados e as limitações de análise. Os resultados estimados são expostos e discutidos e, por fim, apresentam-se as conclusões e sugestôes para pesquisas futuras.

\section{0 mercado brasileiro de motocicletas}

\subsection{0 histórico do mercado}

O histórico do mercado brasileiro de motocicletas pode ser divido em quatro fases. A primeira vai até a década de 1970, quando os modelos comercializados eram predominantemente artesanais ou importados. A segunda fase inicia-se nos anos 1970, quando as empresas japonesas Honda e Yamaha começam as negociações com o governo para a instalação de fábricas no país. Essa fase teve como auge o ano de 1983, quando foram vendidas cerca de 220 mil motocicletas zero km. Mas em decorrência da conjuntura macroeconômica desfavorável (ABRACICLO, 2016), nos anos seguintes as vendas entraram em um processo de retração e se estabilizaram perto de 100 mil unidades ao ano até o início da década de 1990 (Gráfico 1).

\section{GRÁFICO 1}

Vendas anuais de motocicletas produzidas no Brasil - 1988-2013

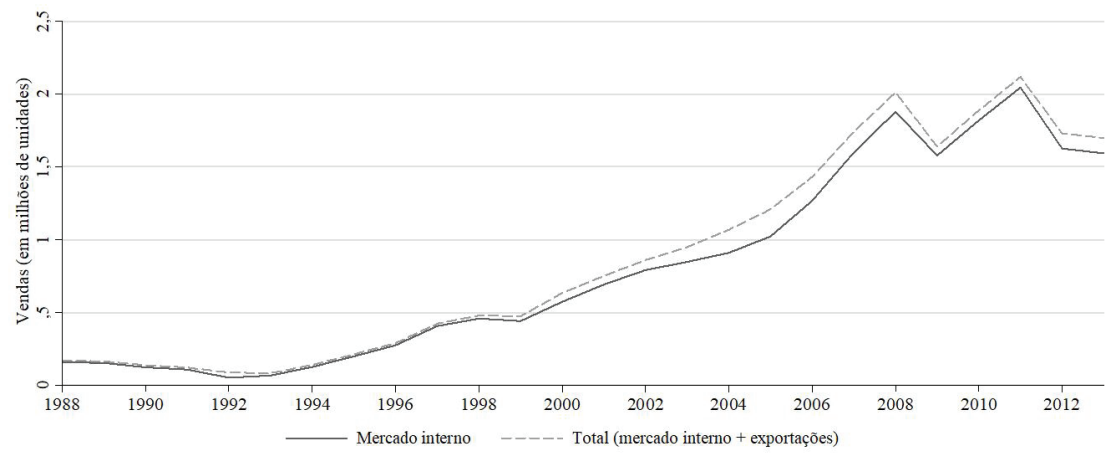

Fonte: Abraciclo. Elaboração dos autores.

Uma terceira fase iniciou-se no meio da década de 1990, quando as vendas começaram a crescer aceleradamente e chegaram perto de 2 milhões em 2008. Por um lado, isso decorreu da expansão da demanda dada pela recuperação do poder de compra e maior facilidade para tomar crédito e participar de consórcios (RIZZI, 2011) e pelo agravamento dos problemas de mobilidade urbana, incentivando o uso 
da moto (SERAPHIM, 2003). Por outro lado, houve incentivo governamental para expansão da oferta, o que se materializou pela fixação das marcas de capital nacional - Kasinski, Sundown, Dafra e Traxx - e pela instalação de fábricas de empresas internacionais - Kawasaki, Suzuki, Harley-Davidson, Triumph e BMW (MELO; VALLE; FALCÃO, 2008; SILVA; CARDOSO; SANTOS, 2011).

Uma quarta fase começou em 2009, quando o mercado sentiu os reflexos da crise dos subprimes e, concomitantemente, foi lançada a motocicleta flex. Naquele ano houve uma redução abrupta nas vendas de modelos zero km, em comparação a 2008, sendo que as vendas do mercado como um todo foram quase $10 \%$ inferiores (Gráfico 1). No entanto, quanto a esta última fase, a Abraciclo (2016) registra alguns fatos relevantes para a manutenção do total de vendas entre 1,5 e 2 milhões de unidades zero $\mathrm{km}$ ao ano, apresentados na sequência.

Primeiro, no período em tela, havia cerca de 20 milhões de motocicletas em circulação no Brasil, o que representava $1 / 4$ da frota nacional de veículos, estimando-se aproximadamente uma motocicleta para cada 11 habitantes. Enquanto isso, países da Europa, como Itália e Grécia, possuíam cerca de uma motocicleta para cada cinco habitantes e países da Ásia, como Tailândia e Indonésia, registravam cerca de uma motocicleta para cada habitante.

Segundo, os dados do Departamento Nacional de Trânsito (Denatran) apontavam a existência de cerca de 28 milhôes de motociclistas habilitados em 2015, ou seja, havia sete motocicletas para cada dez motoristas habilitados para conduzi-las. Nesse sentido, poderia haver uma perspectiva do setor de que ainda haveria mercado a ser disputado pelas empresas, incentivando-as a lançar novos produtos para atrair novos clientes e não perder poder de mercado. Como se pode observar no Gráfico 1, as vendas voltaram a crescer em 2010 e 2011, quando ultrapassaram a casa dos 2 milhões de unidades vendidas. Contudo, esse patamar não se manteve nos anos seguintes e as vendas retornaram para próximo de 1,5 milhão de novas motocicletas por ano.

\subsection{A liderança da Honda}

Outra característica do mercado brasileiro de motocicletas é a existência de uma empresa líder. A Honda detém cerca de $80 \%$ das vendas anuais de motocicletas zero $\mathrm{km}$ desde o fim da década de 1990, seguida pela Yamaha com um share que gira em torno de 15\% (Gráfico 2). Também se observa no Gráfico 2 que as vendas da Honda mostraram uma tendência de leve declínio entre 2003 e 2008, havendo 
uma inflexão em 2009 quando houve a inserção do motor flex. A diferença nas vendas entre 2013 e 2009 é de 5 pontos percentuais.

\section{GRÁFICO 2}

Participação nas vendas de motocicletas zero $\mathrm{km}$, segundo empresas

Brasil - 2003-2013

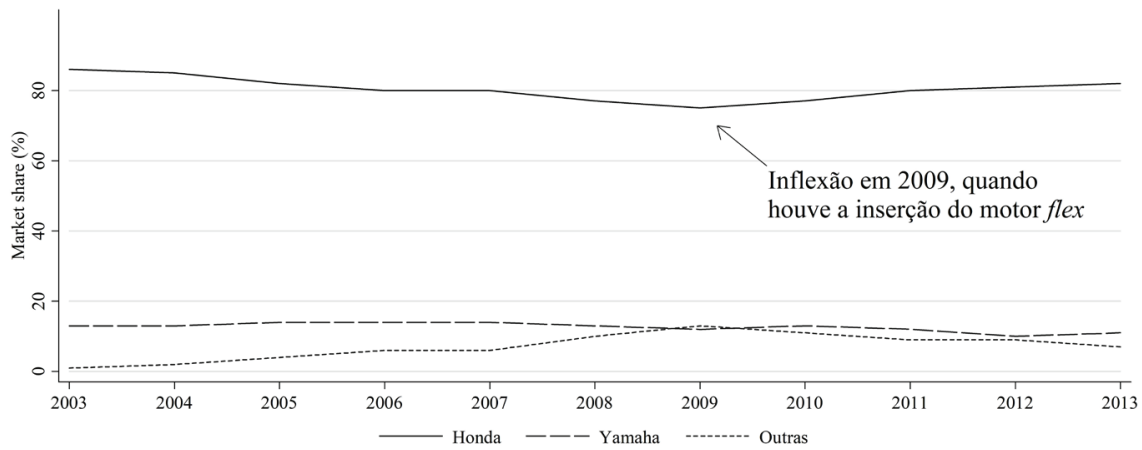

Fonte: Abraciclo. Elaboração dos autores.

A liderança da Honda seria devida a uma estratégia de fortalecimento da marca iniciada na década de 1980 e intensificada nos anos 1990, usando duas ações coordenadas (PASCALE, 1996; MELO; VALLE; FALCÃO, 2008; SILVA; CARDOSO; SANTOS, 2011). A primeira é o Consórcio Nacional Honda (CNH), que possibilita a compra de motocicletas da marca pelos consumidores de menor renda. Nesse sentido, dois indicadores apontam a eficácia desta ação: uma em cada quatro motos da frota nacional foi comprada por meio do $\mathrm{CNH}$; e uma em cada três cotas ativas de consórcio no Brasil em 2015 era do $\mathrm{CNH}{ }^{1}$

A segunda ação está na manutenção de uma ampla rede de concessionárias e distribuidoras de peças, focando especialmente nas cidades de tamanho médio, que centralizam o comércio da empresa no interior do país. Assim, além de espraiar o $\mathrm{CNH}$, a mecânica das suas motos ficou amplamente conhecida, reduzindo os custos de manutenção e garantindo o valor de revenda para os consumidores.

Nesse contexto, a Honda detém os quatro modelos mais vendidos no Brasil: CG 150, BIZ, NXR e CG 125. O Gráfico 3 apresenta as trajetórias de vendas mensais de atacado desses modelos e da YBR da Yamaha (o $5^{\circ}$ mais vendido), assim como a soma das vendas dos outros sete modelos continuamente demandados (no atacado) entre janeiro de 2006 e janeiro de 2013, quais sejam: Hornet e Shadow, da

1 As estatísticas podem ser checadas no Banco Central, em <http://www.bcb.gov.br/?consorciobd>. 
Honda; XT, XTZ, e NEO AT da Yamaha; Comet e Mirage da Kasinski. Estes 12 modelos (destas três marcas) representam aproximadamente 3/4 do total de vendas de motos zero $\mathrm{km}$ no período em análise, apesar de haver mais de 100 modelos disponíveis para venda. ${ }^{2}$

\section{GRÁFICO 3}

Vendas mensais de atacado dos cinco modelos mais demandados e soma das vendas dos outros sete modelos continuamente demandados

Brasil -2006-2013

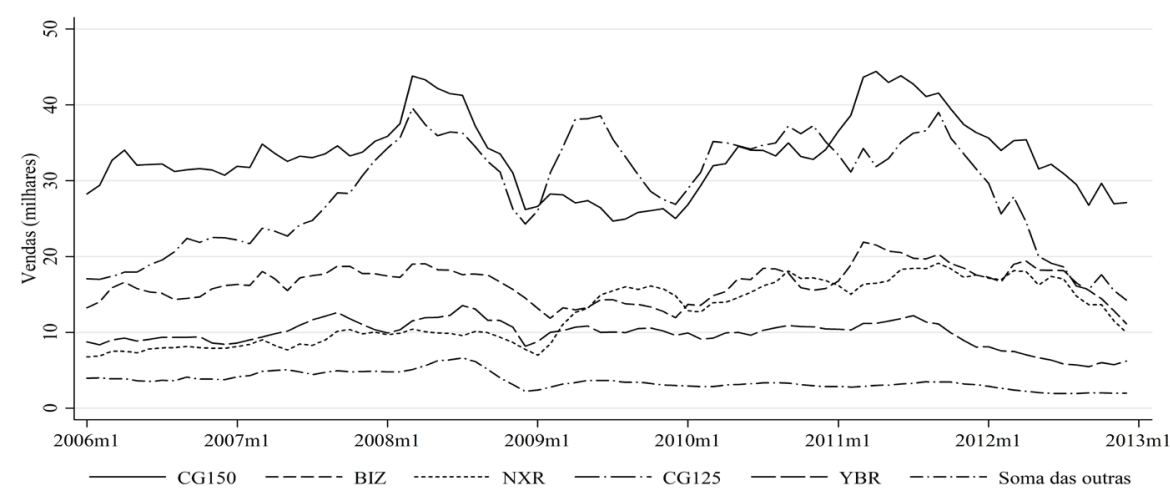

Fonte: Abraciclo. Elaboração dos autores.

\subsection{0 motor flex}

O motor flex é uma inovação que parece seguir um modelo evolucionário e cíclico de mudança tecnológica, que passou a suportar o estabelecimento de um design dominante (NASCIMENTO et al., 2009). Desenvolvido no Brasil para atender ao mercado local (CONSONI, 2004), o motor flex gasolina/etanol surgiu da relação entre fornecedores de autopeças, ${ }^{3}$ montadoras, governo e mercado, somado a um projeto $^{4}$ que buscou substituir a gasolina por um combustível gerado a partir de

2 Com exceção dos casos da Honda e da Yamaha, muitos modelos dos demais fabricantes são lançados e retirados de linha com frequência, o que seria uma consequência da dificuldade em conseguir retirar uma parcela de mercado dos modelos estabelecidos. Vide os Anuários da Abraciclo.

3 No desenvolvimento do motor flex, a descoberta e evolução do sistema de injeção eletrônica (desenvolvido pelas empresas Magnetti Marelli e Bosch) tiveram papel crucial para a utilização concomitante de gasolina e etanol nos veículos (RUSSO; SBRAGIO, 2010). Esse sistema, presente nos carros nacionais desde o final da década de 1980 e nas motocicletas a partir de 2005 (PERA, 2008), permitiu o reconhecimento dinâmico das características da mistura de combustíveis que entram no motor, tornando possível o ajuste dos parâmetros de ignição do sistema e a injeção de combustível correta (BOSCH, 2004).

4 O Proálcool (Programa Nacional do Álcool), lançado em 1975, foi importante para o desenvolvimento de uma forma alternativa de combustível e lidar com a crise do petróleo (SAMANEZ; FERREIRA; NASCIMENTO, 2014). O programa previa 
uma matriz energética própria do território nacional, a cana-de-açúcar, que gerou habilidades prévias na indústria e estrutura logística. ${ }^{5}$

Assim como no passado, quando o setor de duas rodas seguiu o setor automobilístico na utilização de motores movidos a etanol, com o lançamento pela Honda da CG 125 a etanol em 1981 e pela Yamaha da RX 125 em 1982 (INFOMOTO, 2012), as motocicletas novamente seguiram os automóveis ao transformar o sistema de alimentação de seus motores, passando agora para o sistema flex. Mais simples que os automóveis, sendo basicamente identificadas pela marca, categoria ${ }^{6}$ e cilindrada (cc), o motor flex trouxe um diferencial potencialmente relevante para as motocicletas.

Como destacado anteriormente, ao passo que a indústria nacional já possuía a competência do motor a etanol há muito tempo utilizado no país, uma disposição de fornecedores de autopeças, uma ampla rede de postos ofertando gasolina e etanol simultaneamente e pesquisas em andamento, podia-se esperar que em algum momento alguma empresa incorporasse o motor flex na tentativa de ganhar mercado com a diferenciação de produto enquanto a tecnologia se difundisse. De fato, isso ocorreu tanto no caso dos automóveis quanto das motocicletas, e o processo de difusão dentro dos dois mercados se completou em cerca de cinco ou seis anos a partir de seu início.

Dado que em 2009 houve uma retração da demanda, em especial nas vendas da Honda, o motor flex pode ter sido incorporado à CG 150 para evitar reduções no poder de mercado. Ou, analogamente, o lançamento CG 150 flex pode ter ocorrido com o temor do potencial sucesso pioneiro da Yamaha ou da Kasinski. Em ambos os casos, considerando o surgimento de novos concorrentes e as poucas características que diferenciam os produtos, manter o poder de mercado pode ter sido um elemento fundamental na decisão de inovar. ${ }^{7}$

produzir etanol anidro para misturá-lo na gasolina e etanol hidratado para usá-lo em carros movidos exclusivamente a etanol. Esse programa induziu o desenvolvimento de novos motores e componentes e infraestrutura de distribuição, passando a cobrir todo o país (BNDES, 2008). Outros detalhes também em Dahab e Muller (1986) e Brilhante (1997).

5 Para mais detalhes acerca do desenvolvimento e adoção dos motores flex no Brasil, ver Russo e Sbragio (2010), Yu et al. (2010), Consoni (2004), Delgado, Araujo e Fernandes (2007) e Nascimento et al. (2009).

6 Que basicamente são: Motoneta, Scooter, Street, Trail, Big Trail, Naked, Custom, Sport, Crossover, Sport-Touring e Touring.

7 Essa conjectura não foi investigada, já que o foco desse artigo é discutir os aspectos ex-post da inovação. Autores como Possas (1990), Rogers e Olaguera (2003) e Cohen (2010) promovem amplas discussões sobre as potenciais motivaçôes das empresas em inovar. 
A despeito dessas potenciais motivações, após o lançamento da CG 150 Titan Mix a marca também incorporou os motores nos modelos BIZ e NXR. A Yamaha passou a incorporar a tecnologia bicombustível no início de 2013, mesmo ano em que a Kasinski deixou o mercado. Em 2015, as vendas de motocicletas flex zero $\mathrm{km}$ já correspondiam a mais de $60 \%$ das vendas totais, tendo ainda a Honda e a Yamaha como únicas marcas com esse sistema em seus modelos.

Quando se fala de mercado espera-se que os preços tenham papel importante na determinação das vendas; contudo, eles não foram considerados nesta análise. Os motivos principais para isso são: primeiro, há dificuldades em se mensurar os preços dos modelos para o Brasil como um todo e ao longo do tempo, como apresenta a base de dados; ${ }^{8}$ segundo, as vendas das diferentes versões (com preços diferentes) de um mesmo modelo foram somadas, como se fossem um único modelo para viabilizar as estimações.

Como terceiro motivo, tem-se que o consumidor deixa de ter a opção do modelo que escolheu na versão monocombustível a partir do momento que a fábrica inicia a produção do modelo flex, isto é, não existe a escolha do modelo com/sem motor flex, apenas a escolha entre modelos diferentes, que por natureza possuem preços distintos e relacionados às suas características (como categoria, marca e desempenho) e, como quarto e último motivo, a diferença de preço do modelo anterior ao que recebeu a motorização flex é pequena, cerca de $1,5 \%$ na média mais caro de acordo com a divulgação dos preços em revistas especializadas na época dos lançamentos. ${ }^{9}$ Nesse quesito, cabe também destacar que a inflação anual no Brasil ultrapassava os $4 \%$ no período, dificultando a determinação de quanto o motor flex afetou os preços das motocicletas que o adotaram.

\section{Perspectivas de análise da inovação}

As análises de uma inovação, em particular a do motor flex, podem ser vistas nas perspectivas do processo e do impacto. A perspectiva do processo procuraria en-

8 Os preços tendem a variar significativamente de uma regiāo para outra do país, seja por questôes de distância e cobrança de frete, seja por impostos estaduais, poder de mercado das revendas locais, etc.

9 No caso das duas primeiras motocicletas lançadas com o novo motor, divulgou-se na época de seus lançamentos que o preço sugerido da CG 150 flex (versão do modelo entre parênteses) seria de R \$ 6.151 (KS), R \$ 6.683 (ES) e R \$ 7.071 (ESD), enquanto seu modelo anterior, sem motor flex, era de R \$ 6.040 (KS), R \$ 6.590 (ES) e R \$ 6.990 (ESD); e, no caso da NXR flex, o preço seria de R $\$ 7.890$ (KS), R \$ 8.290 (ES) e R \$ 8.690 (ESD), enquanto seu modelo anterior, sem motor flex, era de R \$ 7.590 (KS), R \$ 8.190 (ES) e R 8.690 (ESD). Disponível em: <https://carros.uol.com.br/ultnot/2009/06/19/ult5498u224.jhtm>, <https:// carros.uol.com.br/ultnot/2009/01/16/ult5498u172.jhtm>, <https://carros.uol.com.br/motos/noticias/redacao/2010/06/28/ nxr-150-bros-mix-vai-de-alcool-e-gasolina.htm>, <https://carros.uol.com.br/ultnot/2009/03/16/ult5498u192.jhtm>. 
tender motivação, desenvolvimento e adoção da inovação, enquanto a do impacto buscaria estimar seus resultados ex-post em indicadores da empresa inovadora e/ ou do mercado, por exemplo, vendas. Rogers e Olaguera (2003), Cohen (2010) e Mairesse e Mohnen (2010) revisam a literatura que contém tais análises, em ambas as perspectivas e diversos contextos.

No caso específico da inovação do motor flex, Nichols (2003), Mello e Marx (2007), Lima (2009), Nascimento et al. (2009, 2012), Amatucci e Spers (2012), Vazzolér et al. (2012), Hira e Oliveira (2009), Oliva et al. (2014) e Moraes e Bacchi (2014) promovem análises de processo mostrando que o desafio tecnológico estava posto para a indústria nacional de automóveis e de motocicletas desde o fim da década de 1970, mas que a ideia só se tornou viável no início dos anos 2000.

Quanto ao impacto da inovação do motor flex, na revisão da literatura verificou-se que DeSouza, Petterini e Miro (2010) usam modelos baseados em escolhas dos agentes para estudar vários aspectos do mercado de automóveis. Em particular, os autores notam que os modelos que permaneceram monocombustível no período 2004-2008 teriam perdido cerca de 30\% nas suas vendas por conta disso.

Willinger (2012) discute as dificuldades existentes em se isolar, o que é resultado específico da inovação. Segundo o autor, quando a Volkswagen inovou ao lançar o Gol 1.6 flex houve um crescimento de 38\% nas vendas deste modelo. ${ }^{10}$ Concorrentes diretos, o Fiat Palio 1.6 e o Ford Fiesta 1.6 tiveram um crescimento de $20 \%$ nas vendas no mesmo período. Então, contemporaneamente ao lançamento da tecnologia flex pode ter existido um aumento da preferência pelos modelos 1.6 el ou um aumento generalizado das vendas. Por consequência, só parte do crescimento das vendas do Gol 1.6 decorreria da inovação.

Uma forma simples de tentar isolar o resultado específico da inovação seria com análise de regressão. Se o pesquisador dispõe de uma base de dados em que parte das unidades observadas foi inovada (grupo de tratamento) e parte não (grupo de controle), uma forma de se inferir um "efeito causal médio" seria estimar a regressão $Y_{i}=\beta_{0}+\beta_{1} T_{i}+\sum_{k} \beta_{k} X_{k i}+\varepsilon_{i}$, em que $Y_{i}$ é o valor observado do indicador de impacto da unidade $i$; $\beta$ 's são parâmetros; $T_{i}=1$ é uma $d u m m y$ indicando o pertencimento ao grupo de tratamento; $X_{k i}$ são covariadas; e $\varepsilon_{i}$ é o erro. Nesse caso, $\beta_{0}$ representa a média condicionada do grupo de controle e $\beta_{1}$ pode representar o efeito causal médio da inovação controlando-se pelas covariadas. A palavra pode é frisada porque a estimativa de $\beta_{1}$ é uma medida de efeito causal médio se, como condição necessária,

10 Comparando os 12 meses anteriores e posteriores da mudança de motor com os dados de emplacamentos zero km do Denatran. 
a definição das unidades tratadas for ortogonal aos valores do indicador de impacto, o que é detalhadamente discutido em Rubin (2005).

Todavia, como raramente isso acontece no caso de uma inovação tecnológica, tais procedimentos per se raramente geram estimativas consistentes nas análises de impacto. ${ }^{11}$ Por conta disso, nos anos recentes há um esforço na literatura para o desenvolvimento de técnicas mais adequadas para as análises de impacto, sendo que praticamente todas partem do arcabouço de inferência causal de Neyman-Rubin, também conhecido como "modelo de resultados potenciais". ${ }^{12}$

Nesse arcabouço, $Y_{i}^{(1)}$ denota o resultado de um indicador de impacto (e.g., vendas) se a unidade $i$ (e.g., CG 150) receber um tratamento (e.g., motor flex), denota o resultado se a unidade não recebe o tratamento, e o efeito causal é definido pela diferença entre $Y_{i}^{(1)}$ e $Y_{i}^{(0)}$. Assim, o problema fundamental de inferência causal é que se observa apenas $Y_{i}^{(1)}$ ou $Y_{i}^{(0)}$ para cada unidade $i$, sendo o valor observado o "factual" e outro o "contrafactual" (RUBIN, 2005).

\section{Metodologia}

Como discutido em Imbens e Wooldridge (2009), as técnicas mais comuns que decorrem do arcabouço de inferência causal de Neyman-Rubin (pareamento associado com modelos econométricos de diferenças-em-diferenças, por exemplo) seriam adequadas para estimar os contrafactuais quando há muitas unidades tratadas. Porém, quando existem poucas unidades tratadas, as técnicas de pareamento reduzem excessivamente o número de graus de liberdade para as metodologias baseadas em análises de regressão. É o caso desse exercício, já que a Honda incorporou o motor flex na CG 150 em março de 2009, depois na NXR em agosto do mesmo ano e na BIZ em janeiro de 2011.

\subsection{0 controle sintético}

Nesses casos, Imbens e Wooldridge (2009) sugerem a utilização da técnica do "controle sintético", que começa com a definição dos valores do indicador de impacto (e.g., vendas) com e sem a inovação, $Y_{i}^{(1)}$ e $Y_{i}^{(0)}$ e, respectivamente, onde indica o tempo. Como nenhuma unidade seria tratada no período pré-inovação, ocorreria $Y_{i}^{(1)}=Y_{i}^{(0)}$ para todo $i$. Consequentemente, definindo uma dummy $I_{i t}=1$ se $i=i^{*}$

11 Ver Willinger (2012).

12 Detalhes em Imbens e Wooldridge (2009). 
é um modelo tratado, o valor do indicador de impacto no período pós-inovação seria $Y_{i t}=Y_{i}^{(0)}+\alpha_{t} I_{i t}$, em que $\alpha_{t}$ seria o efeito causal da inovação.

Para estimar $\alpha_{\mathrm{t}}$, Abadie, Diamond e Hainmueller (2010) propõem que se considere $Y_{i}=\theta_{\mathrm{t}} Z_{i}+\xi_{i t}$, em que $\theta_{\mathrm{t}} \mathrm{e} Z_{i}$ são vetores linha de parâmetros e coluna de covariadas, respectivamente, e $\xi_{i t}$ é um termo que agrega fatores temporais, erros e omissōes. Dessa forma, os autores demonstram que se (a) há um número suficientemente grande de períodos pré-inovação observados e (b) existem pesos $\mathrm{w}_{i} \geq 0$ para todo $i \neq i^{*}$, tais que $\sum_{\neq i} W_{i}=1, \sum_{i \neq i^{*}} W_{i} Y_{i^{*}}=Y_{i^{*} t}$ e $\sum_{i \neq *^{*}} W_{i} Z_{i}=Z_{i^{*}}$ para todo o período pré-inovação, então um estimador de efeito causal é $\widehat{\alpha}_{t}=Y_{i^{*} t}-\sum_{\neq i *} W_{i} Y_{i t}$, em que $\sum_{\nexists i} * \mathrm{~W}_{i} Y_{i t}$ é denominado de "sintético" de $Y_{i^{*} t}$ e sua trajetória representaria aquela contrafactual à inovação.

Os exercícios de Abadie, Diamond e Hainmueller (2010, 2011, 2015) sugerem que são necessários ao menos 20 períodos para satisfazer a condição (a), o que é factível com os dados da Abraciclo. Complementarmente, os autores propõem o critério da minimização da soma dos quadrados ponderados dos desvios das condições (b) para determinar os pesos do sintético, $w_{i}$, da seguinte forma:

$$
\begin{array}{cc}
\begin{array}{c}
\text { Min. para todo } w_{i} \text { tal que } i \neq i^{*} \\
\text { e todo } q_{k} \text { tal que } k=0, \ldots, K
\end{array} & q_{0}\left(\bar{Y}_{i^{*}}-\sum_{i \neq i^{*}} w_{i} \bar{Y}_{i}\right)^{2}+\sum_{k=1}^{K} q_{k}\left(z_{k i^{*}}-\sum_{i \neq i^{*}} w_{i} z_{k i}\right)^{2} \\
\text { s.r. } & \sum_{i \neq i^{*}} w_{i}=1 ; \sum_{k=0}^{K} q_{k}=1
\end{array}
$$

em que $q_{k}$ são as ponderações determinadas dentro do procedimento de minimização; $\bar{Y}_{i}$ é a média do indicador de impacto nos períodos pré-intervenção; $K$ é o número de covariadas consideradas; $z_{k i} \in Z_{i}$, podendo ser médias das covariadas; e, para se fazer a inferência de $\widehat{\alpha}_{t}$ decorrente dos valores de $w_{i}$, é possível proceder com a comparação de resultados de validação cruzada, ou seja, retira-se sequencialmente alguma unidade de controle e encontram-se novas soluções para a equação (1). Se as soluções forem semelhantes, isso indicaria que o sintético estimado de fato representaria o resultado contrafactual. O modelo completo encontra-se no Apêndice I.

\subsection{Desafios e limitações do controle sintético}

Considerando-se as peculiaridades do mercado de motocicletas e dos dados da Abraciclo, quatro desafios dificultaram e limitaram a operacionalização da metodologia. 
O primeiro refere-se ao fato de ser necessário um painel balanceado no indicador de impacto para testar se as trajetórias pré-intervenção das vendas de um modelo tratado são adequadamente sintetizadas, isto é, para verificar se $Y_{i^{*} t} \cong \sum_{i \neq i^{*}} w_{i} Y_{i t}$ nos períodos pré-intervenção, o que indicaria que o sintético se aproximaria do contrafactual nos períodos pós-intervenção. Considerando isso, 12 modelos que atendem a essa restrição foram selecionados. Cabe destacar que as vendas anuais desses modelos representam aproximadamente $3 / 4$ das vendas ${ }^{13}$ totais de motocicletas zero $\mathrm{km}$ no período analisado, como pode ser visto na Tabela 1 .

\section{TABELA 1}

Vendas anuais de atacado de motocicletas

Brasil - 2006-2012

\begin{tabular}{c|c|c|c}
\hline Ano & $\begin{array}{c}\text { Vendas da indústria } \\
(\mathbf{e m ~ m i l )}\end{array}$ & $\begin{array}{c}\text { Vendas dos 12 } \\
\text { modelos considerados } \\
(\mathbf{e m} \text { mil) } \mathbf{( B )}\end{array}$ & B/A (\%) \\
\hline 2006 & $1.268,0$ & $1.028,7$ & 81,13 \\
2007 & $1.600,2$ & $1.193,5$ & 74,58 \\
2008 & $1.879,7$ & $1.407,5$ & 74,88 \\
2009 & $1.579,2$ & $1.175,3$ & 74,42 \\
2010 & $1.818,2$ & $1.332,5$ & 73,29 \\
2011 & $2.044,5$ & $1.514,9$ & 74,10 \\
2012 & $1.625,5$ & $1.116,7$ & 68,70 \\
\hline
\end{tabular}

Fonte: Abraciclo. Elaboração dos autores.

O segundo desafio é que a CG 150 é a motocicleta mais vendida do Brasil. Portanto, é impossível descrever sua trajetória de vendas (per se) por uma combinação linear convexa das trajetórias dos outros modelos e, consequentemente, atender ao pressuposto $\sum_{i \neq i^{*}} w_{i} Y_{i t}=Y_{i^{*} t}$ para $\sum_{i \neq i^{*}} w_{i}=1$. Mas, como as trajetórias de vendas guardam bijeção com números índice, $\stackrel{i \neq i}{i}$ controle sintético pode ser aplicado sem perda de generalidade sobre eles para se estimarem os contrafactuais, como em Carrasco, Mello e Duarte (2014).

Para notar isso, considere o seguinte exemplo: se em um período pós-intervenção o índice de vendas de uma motocicleta inovada $\left(Y_{i^{*} t}\right)$ é 150 e o sintético $\left(\sum_{i \neq i^{*}} w_{i} Y_{i t}\right)$ é 100 , então as vendas que decorreriam da inovação nesse momento seriam dadas

13 As médias anuais das vendas mensais no atacado dos modelos utilizados na análise e suas características encontram-se no Anexo I. 
por $\left[\left(Y_{i^{*} t}-\sum_{i \neq i^{*}} w_{i} Y_{i t}\right) / 100\right] V_{i 0}=0,5 V_{i 0}$, onde $V_{i 0}$ é o número de motocicletas vendidas no período de base. Então, considerando $t^{*}$ o mês de lançamento da motocicleta flex, o contrafactual das vendas seria:

$$
\sum_{t \geq t^{*}}\left(\frac{Y_{i^{*} t}-\sum_{i \neq i{ }^{*}} w_{i} Y_{i t}}{100}\right) V_{i 0}
$$

Assim, utilizando o valor das vendas de janeiro de 2006 como base (igual a 100), o resultado da transformação das vendas em números-índice é ilustrado no Gráfico 4.

\section{GRÁFICO 4}

Número-índice das vendas dos modelos da amostra

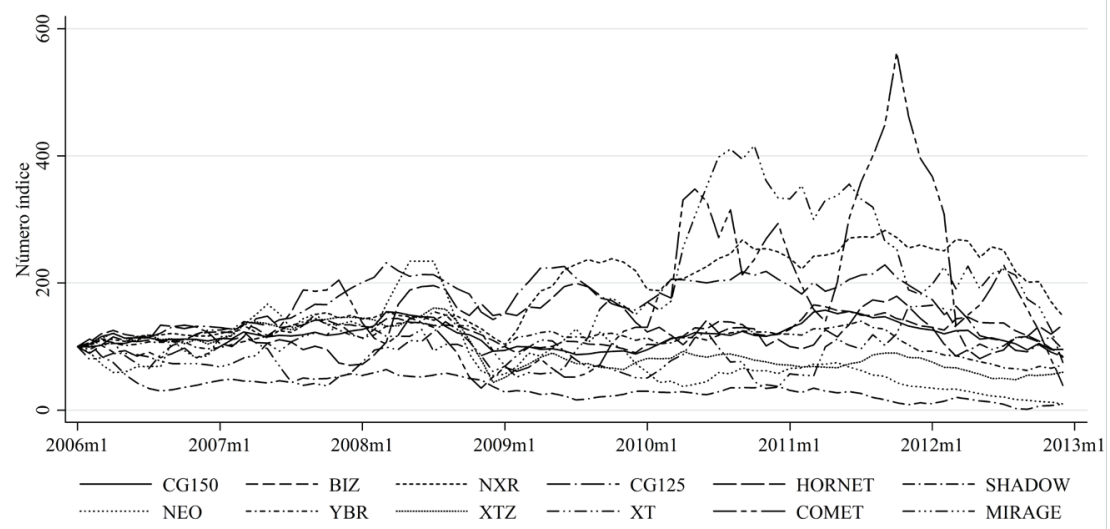

Fonte: Abraciclo. Elaboração dos autores.

O terceiro desafio relaciona-se com as covariadas $\left(Z_{i}\right)$, já que as motocicletas possuem poucas características observáveis na perspectiva do pesquisador, mas existem características qualitativas importantes e não observáveis, como confiança na marca e design. Além disso, a Abraciclo não disponibiliza a desagregação das vendas por região, e os preços das motocicletas, da gasolina e do etanol variam de um estado para outro, devido aos valores do frete, tributos incidentes, etc. (MELO; SAMPAIO, 2014). Assim, a alternativa possível é utilizar como preditores as próprias vendas, as cilindradas e a potência das motocicletas, já que estas duas últimas são intrínsecas ao modelo. ${ }^{14}$ Nesse sentido, é importante notar que, apesar de cilindradas e

14 As cilindradas de cada motocicleta encontram-se no próprio relatório de vendas disponibilizado pela Abraciclo e a potência foi obtida na ficha técnica de cada motocicleta disponibilizada pelas montadoras. 
potência serem altamente correlacionadas, isso não causa nenhum problema para a determinação dos pesos na resolução do problema (1). ${ }^{15}$

O quarto desafio é uma limitação analítica da aplicação do controle sintético nesse caso, já que não é possível identificar entre quais modelos as potenciais substituiçôes de consumo se deram. ${ }^{16} \mathrm{Ou}$ seja, se as vendas contrafactuais estimadas da CG 150 (ou da BIZ, ou da NXR) são menores que as factuais, isso indicaria que outro modelo do mercado pode não ter sido demandado em detrimento da motorização flex. Mas com a metodologia do controle sintético não é possível identificar isso, e tampouco se este modelo seria fabricado pela própria Honda (e.g., CG 125) ou por qualquer outra marca. Em suma, a metodologia limita-se a promover comparações de trajetórias de vendas e assim busca estimar situaçôes contrafactuais.

\section{Resultados e discussão}

Os pesos do controle sintético, $w_{i}$, foram determinados pela resolução do problema (1) usando os dados mensais das vendas no atacado das motocicletas divulgados pela Abraciclo ${ }^{17}$ e a rotina "synth" apresentada por Abadie, Diamond e Hainmueller (2011).

Assim, a Tabela 2 mostra que, no caso da CG 150, a ponderação das trajetórias é: $11,2 \%$ para CG $125 ; 46,5 \%$ para a YBR; $29,7 \%$ para a XTZ; $12,6 \%$ para a XT; e $0 \%$ para os demais modelos do grupo de controle. ${ }^{18}$ Quanto à sintetização das vendas contrafactuais da BIZ, três modelos receberam pesos: a YBR com 67,7\%; a XTZ com 25,8\%; e a Mirage com 6,4\% do total. Quanto à NXR, também três modelos receberam pesos: a CG 125 com 40,01\%; a Hornet com 8,6\%; e a YBR com $51,3 \%$.

15 Abadie, Diamond e Hainmueller $(2010,2011,2015)$ mostram que multicolinearidade não é um problema para o controle sintético, já que sua inferência é feita por meio de testes de validação cruzada.

16 Como fazem DeSouza, Petterini e Miro (2010) no caso dos automóveis, já que dispunham de uma base de dados mais elaborada para programar modelos baseados em escolhas dos agentes.

17 Média anual das vendas mensais apresentadas no Anexo I.

18 No controle sintético, o grupo de controle é igualmente chamado de "grupo de doadores", termo também utilizado em outros momentos no texto. 
TABELA 2

Pesos do controle sintético, $\boldsymbol{w}_{\boldsymbol{i}}$, encontrados na resolução do problema (1)

\begin{tabular}{cccccc}
\hline Montadoras & Modelos & CG 150 & BIZ 125 & NXR 150 \\
\hline \multirow{3}{*}{ Honda } & CG 125 & 0,112 & 0 & 0,401 \\
& Hornet 600 & 0 & 0 & 0,086 \\
& Shadow 750 & 0 & 0 & 0 \\
& Neoat 115 & 0 & 0 & 0 \\
& YBR 125 & 0,465 & 0,677 & 0,513 \\
Yamaha & XTZ 125 & 0,297 & 0,258 & 0 \\
& XT 660 & 0,126 & 0 & 0 \\
& Comet 250 & 0 & 0 & 0 \\
Kasinski & Mirage 250 & 0 & 0,064 & 0 \\
\hline
\end{tabular}

Fonte: Abraciclo. Elaboração dos autores.

A Tabela 3 ilustra o balanço dos preditores no período pré-inovação, isto é, a consistência dos pressupostos $\bar{Y}_{i^{*}}=\sum_{i \neq i^{*}} w_{i} \bar{Y}_{i}$ e $\sum_{i \neq i^{*}} w_{i} Z_{i}=Z_{i^{*}}$. Enquanto a média do índice de venda factual da CG 150 é 117,6, a combinação linear dos índices de venda da CG 125, da YBR, da XTZ e da XT com os pesos da Tabela 2 gera o índice de venda sintético da CG 150 em 118,1 no período pré-inovação. Complementarmente, as cilindradas e a potência da CG 150 são mimetizadas pela mesma combinação linear nas características destes quatro modelos, indicando um bom ajustamento do controle sintético, tendo apenas as cilindradas como exceção. E o análogo ocorre para a BIZ e a $\mathrm{NXR}$, apontando um bom ajustamento do exercício de sintetização como um todo. ${ }^{19}$

TABELA 3

Balanço dos preditores, que indicam a consistência do ajuste $\bar{Y}_{i^{*}}=\sum_{i \neq i^{*}} w_{i} \bar{Y}_{i}$ $\mathrm{e} \sum_{i \neq i^{*}} w_{i} Z_{i}=Z_{i^{*}}$ para o período pré-inovação

\begin{tabular}{l|c|c|c|c|c|c}
\hline \multirow{2}{*}{ Preditor } & \multicolumn{2}{c|}{ CG 150 } & \multicolumn{2}{c|}{ BIZ 125 } & \multicolumn{2}{c}{ NXR 150 } \\
\cline { 2 - 7 } & Factual & Sintética & Factual & Sintética & Factual & Sintética \\
\hline Índice das vendas & 117,6 & 118,1 & 123,0 & 123,3 & 157,5 & 160,1 \\
Cilindradas & 150,0 & 192,4 & 125,0 & 132,8 & 150,0 & 165,7 \\
Potência & 14,2 & 15,0 & 9,1 & 11,3 & 13,8 & 18,6 \\
\hline
\end{tabular}

Fonte: Abraciclo. Elaboração dos autores.

19 Uma discussão detalhada sobre os ajustamentos adequados pode ser consultada em Abadie, Diamond e Hainmueller (2010, $2011,2015)$. 
O Gráfico 5 apresenta as trajetórias dos índices de vendas factual e sintético da CG 150. Notam-se traçados semelhantes no período pré-intervenção (até março de 2009, marcado pela barra cinza na vertical), o que reflete o bom ajustamento da sintetização. Além disso, percebe-se que as vendas da "CG 150 sintética” são superiores às da "CG 150 factual" após a implementação do motor, o que indicaria que a motocicleta flex não obteve sucesso imediato no seu lançamento, mas teve algum tempo depois.

Esse indício é corroborado por matérias de jornais que noticiaram o lançamento e registraram as primeiras impressões dos consumidores na época, destacando que que havia uma desconfiança em relação à tecnologia flex nas motocicletas. ${ }^{20}$

\section{GRÁFICO 5}

Controle sintético da CG 150 - em números-índice - 2006-2009

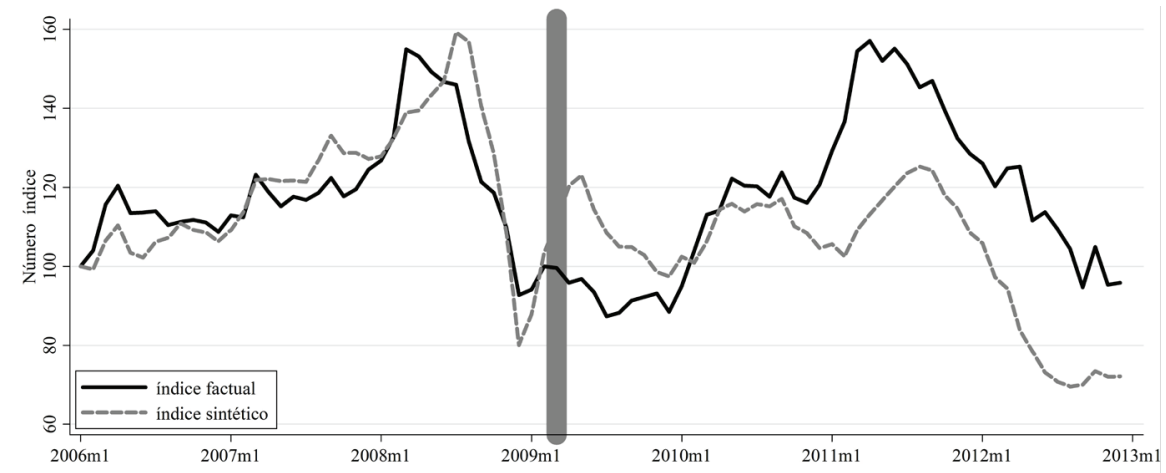

Fonte: Abraciclo. Elaboração dos autores.

Analogamente, o Gráfico 6 apresenta os índices de venda factual e sintético da BIZ, notando-se também trajetórias semelhantes no período pré-intervenção (até janeiro de 2011). Além disso, após o lançamento da BIZ flex, o índice factual logo se afasta do sintético e permanece assim até o fim do período analisado. Assim, considerando a discussão anterior, infere-se que nesse caso a potencial desconfiança dos consumidores poderia ter desaparecido e que a BIZ teria vendido menos na ausência da inovação. 
GRÁFICO 6

Controle sintético BIZ 125 - em números-índice - 2006-2013

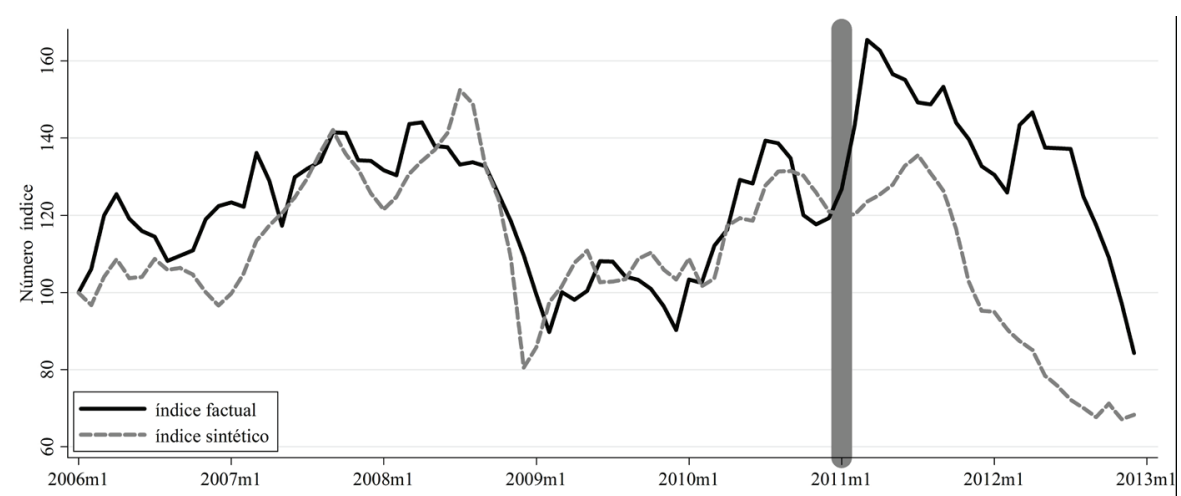

Fonte: Abraciclo. Elaboração dos autores.

Os resultados da NXR são ilustrados no Gráfico 7. Percebe-se um descolamento significativo das trajetórias dos índices factual e sintético ainda no primeiro trimestre de 2009, permanecendo descoladas nos períodos subsequentes. Este descolamento anterior à incorporação do motor flex (em novembro de 2009) pode decorrer de modificaçôes no design e nos sistemas eletrônicos incorporados ao modelo em fevereiro de 2009. Logo, com base nesses fatores, é importante notar a que os resultados indicam que a NXR teria vendido menos na ausência da inovação, embora a diferença entre o factual e o sintético observada no Gráfico 7 também possa ser parcialmente atribuída aos fatores modificados em fevereiro de 2009.

\section{GRÁFICO 7}

Controle sintético NXR 150 - em números-índice - 2006-2013

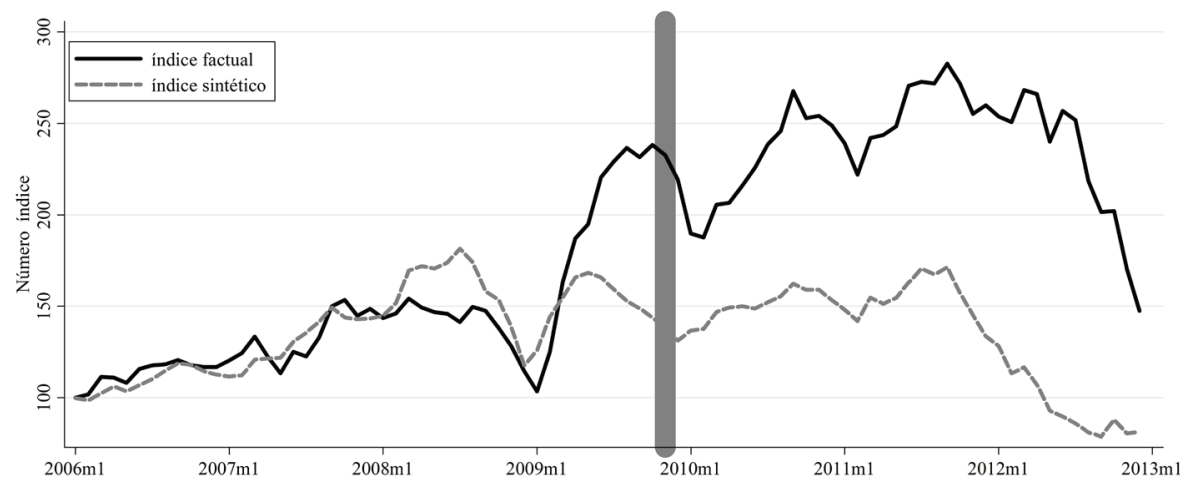

Fonte: Abraciclo. Elaboração dos autores. 
No Apêndice II são apresentados testes de validação cruzada que corroboram a consistência dos resultados apresentados. Assim, o exercício indica consistentemente que a incorporação do motor flex foi relevante para que a Honda mitigasse perdas nas vendas no período 2009-2012, já que as trajetórias dos índices factuais se mostraram acima dos sintéticos e estes estariam indicando os contrafactuais da inovação.

A partir dos resultados, é possível estimar as vendas que a Honda teria perdido no quadriênio 2009-2012 caso não tivesse adotado o novo motor. Para tanto, considerando a equação (2) apresentada anteriormente, a Tabela 4 mostra as vendas factuais e contrafactuais estimadas de cada modelo e para a Honda - somando-se as vendas de todos os seus modelos.

Pelo exercício, o motor flex na CG 150 teria resultado uma elevação de 12,9\% em comparação com o caso monocombustível. ${ }^{21}$ Em decorrência da inovação, a BIZ teria suas vendas elevadas em $37 \%$ na comparação com seu contrafactual, analisando-se dois anos de vendas, 2011 e 2012. O resultado obtido para a NXR (77\%) foi significativamente superior ao observado para as outras duas motocicletas, no período entre o início das vendas com o motor bicombustível e o final de 2012. Contudo, como discutido anteriormente, a NXR teve suas vendas afetadas por efeitos adversos ao da utilização do novo motor, mascarando o efeito exclusivo da inovação.

TABELA 4

Vendas estimadas e contrafactuais (em milhares) e percentual das vendas atribuídas ao motor flex

Brasil - 2009-2012

\begin{tabular}{|c|c|c|c|c|c|c|c|c|}
\hline \multirow{2}{*}{ Anos } & \multicolumn{2}{|c|}{ CG 150} & \multicolumn{2}{|c|}{ BIZ 125} & \multicolumn{2}{|c|}{ NXR 150} & \multicolumn{2}{|c|}{$\begin{array}{c}\text { Honda (todos os } \\
\text { modelos) }\end{array}$} \\
\hline & Factual & $\begin{array}{l}\text { Contra- } \\
\text { factual }\end{array}$ & Factual & $\begin{array}{l}\text { Contra- } \\
\text { factual }\end{array}$ & Factual & $\begin{array}{l}\text { Contra- } \\
\text { factual }\end{array}$ & Factual & $\begin{array}{l}\text { Contra- } \\
\text { factual }\end{array}$ \\
\hline 2009 & 262 & 307 & - & - & 31 & 18 & 292 & 325 \\
\hline 2010 & 391 & 374 & - & - & 185 & 122 & 577 & 497 \\
\hline 2011 & 489 & 391 & 235 & 193 & 208 & 126 & 932 & 709 \\
\hline 2012 & 375 & 271 & 197 & 123 & 184 & 77 & 757 & 472 \\
\hline Total & 1.515 & 1.343 & 433 & 316 & 609 & 344 & 2.558 & 2.003 \\
\hline $\begin{array}{l}\% \text { das } \\
\text { vendas }\end{array}$ & \multicolumn{2}{|c|}{12,9} & \multicolumn{2}{|c|}{37,0} & \multicolumn{2}{|c|}{77} & \multicolumn{2}{|c|}{27,0} \\
\hline
\end{tabular}

Fonte: Abraciclo. Elaboração dos autores.

21 Note-se que, considerando o apresentado no Gráfico 5, as vendas para 2009 foram inferiores às de seu contrafactual. 
A despeito disso, considerando a NXR na avaliação geral, o exercício indica que a Honda teria vendido $27 \%$ a mais de novas motocicletas por ter inovado. Alternativamente, excluindo a NXR na avaliação geral, o exercício indica que a empresa teria vendido 1,95 milhão motocicletas com a inovação e 1,66 milhão no caso contrário. Ou seja, mesmo com uma análise menos otimista, o exercício indica que a Honda teve um acréscimo de $17 \%$ nas vendas no período por conta da inovação.

\section{Considerações finais}

O exercício aqui apresentado indica que a incorporação do motor flex foi relevante para a Honda mitigar perdas nas vendas de motocicletas no período 2009-2012. Em associação ao fato de que a empresa ganhou cinco pontos percentuais em parcela de mercado no período, isso corrobora a conjectura de que a inovação foi relevante para a Honda aumentar sua liderança na fase pós "crise dos subprimes".

Para além do exercício, cabe registrar que durante sua construção observou-se que o mercado brasileiro de motocicletas ainda é pouco analisado pela literatura, embora este tipo de veículo esteja muito presente nos cotidianos urbano e rural do país. Nesse sentido, verificou-se também que a Abraciclo disponibiliza várias informações ainda pouco analisadas, em que algumas peculiaridades parecem suscitar futuras pesquisas.

Por exemplo, o mercado cresceu de forma exponencial entre 1994 e 2008, estagnou depois de 2009, mas ainda apresenta a impressionante marca de mais de 1,5 milhão de novas unidades vendidas ao ano, sem que se tenha encontrado qualquer discussão mais aprofundada sobre seu tamanho potencial. Alinhado a isso, constatou-se que o mercado é intrinsecamente relacionado aos sistemas de consórcio, mas também não se encontrou nenhuma discussão acadêmica a esse respeito, tampouco sobre a estratégia da Honda em explorar isso para manter sua liderança no Brasil.

Embora os dados da Abraciclo não apresentem desagregações das vendas por regiōes do país, uma futura pesquisa talvez possa explorar os dados de emplacamentos do Denatran nesse sentido. Caso isso se mostre viável, talvez seja possível usar modelos analíticos mais explicativos, a exemplo do que fizeram DeSouza, Petterini e Miro (2010) para o caso dos automóveis, permitindo uma modelagem de concorrência com empresa líder e firmas entrantes, considerando diferenças de preços locais de combustíveis, tributação, frete, etc. Em suma, registra-se aqui a percepção de uma potencial agenda de pesquisa empírica ainda inexplorada sobre o mercado brasileiro de motocicletas. 


\section{Referências bibliográficas}

ABADIE, A.; DIAMOND, A.; HAINMUELLER, J. Synthetic control methods for comparative case studies: estimating the effect of California's Tobacco Control Program. Journal of the American Statistical Association, v. 105, n. 490, p. 493-505, 2010.

. Synth: an R Package for synthetic control methods in comparative case studies. Journal of Statistical Software, v. 42, n. 13, p. 1-17, 2011.

. Comparative politics and the synthetic control method. American Journal of Political Science, v. 59, n. 2, p. 495-510, 2015.

ABRACICLO - Associação Brasileira dos Fabricantes de Motocicletas, Ciclomotores, Motonetas, Bicicletas e Similares. 40 anos da ABRACICLO e do polo duas rodas de Manaus. Manaus, 2016. Disponível em: <http://www.abraciclo.com.br>. 2016.

AMATUCCI, M.; SPERS, E. E. Institutional, technological and commercial innovations in the Brazilian ethanol and automotive industries. In: CALABRESE, G. The greening of the automotive industry. London: Palgrave Macmillan UK, 2012. p. 164-184.

ANDERSON, L. G. Ethanol fuel use in Brazil: air quality impacts. Energy \& Environmental Science, v. 2, p. 1015-1037, 2009.

BOSCH, R. Bosch automotive handbook. 6. ed. Plochingen, Alemanha, 2004.

BNDES. Bioetanol de cana-de-açúcar: energia para o desenvolvimento sustentável. Rio de Janeiro: BNDES, 2008.

BRILHANTE, O. M. Brazil's Alcohol Programme: from an attempt to reduce oil dependence in the seventies to the green arguments of the nineties. Journal of Environmental Planning and Management, v. 40, n. 4, p. 435-449, 1997.

CARrasCO, V.; MELLO, J. M. P.; DUARTE, I. A década perdida: 2003-2012. Rio de Janeiro: Departamento de Economia da PUC-RIO, 2014 (Texto para discussão, n. 626).

COHEN, W. M. Fifty years of empirical studies of innovative activity and performance. Handbook of the Economics of Innovation. Elsevier, 2010. p. 129-213.

CONSONI, F. L. Da tropicalização ao projeto de veículos: um estudo das competências em Desenvolvimento de produtos nas montadoras de automóveis no Brasil. 2004. 269 f. Tese. (Doutorado em Política Científica e Tecnológica) - Instituto de Geociências, Universidade Estadual de Campinas, Campinas, 2004.

DAHAB, S. S.; MULLER, H. Difusão de novos produtos: o caso do carro a álcool no Brasil. In: XIV ENCONTRO NACIONAL DE ECONOMIA. Anais... Brasília: Anpec, 1986. p. 533-559. 
DESOUZA, S. A.; PETTERINI, F. C.; MIRO, V. H. A Tributação nas vendas de automóveis no Brasil: quem paga a maior parte da conta? Revista EconomiA, v. 11, n. 3, p. 559-596, set./dez. 2010.

HIRA, A.; OLIVEIRA, L. G. No substitute for oil? How Brazil developed its ethanol industry. Energy Policy, v. 37, n. 6, p. 2450-2456, 2009.

IMBENS, G. W.; WOOLDRIDGE, J. M. Recent developments in the econometrics of program evaluation. Journal of Economic Literature, v. 47, n. 1, p. 5-86, 2009.

LIMA, P. C. R. Os carros flex-fuel no Brasil. Consultoria Legislativa, Nota Técnica (sem número) da área de Recursos Minerais, Hídricos e Energéticos, 2009.

MACIEIRA, F. D. Motocicleta: a evolução das máquinas que conquistaram o mundo. São Paulo: Editora Alaúde, 2009.

MAIRESSE, J.; MOHNEN, P. Using innovation surveys for econometric analysis. Handbook of the Economics of Innovation. Elsevier, 2010. p. 1129-1155.

MELLO, A. M.; MARX, R. Innovative capacity maintenance by automakers in a product development outsourcing scenario: the case of VW in Brazil. International Journal of Automotive Technology and Management, v. 7, n. 2/3, p. 200-215, 2007.

MELO, E. L.; VALLE, I.; FALCÃO, C. M. Novas formas de organização da produção e do trabalho: formação de redes de produção na Honda. Novos Cadernos NAEA, v. 11, n. 2, p. 139-154, 2008.

MELO, A.; SAMPAIO, Y. Impactos dos preços da gasolina e do etanol sobre a demanda de etanol no Brasil. Revista de Economia Contemporânea, v. 18, n. 1, p. 56-83, 2014.

MORAES, M. L.; BACCHI, M. R. Etanol: do início às fases atuais de produção. Revista de Política Agrícola, v. 23, n. 4, p. 1-24, 2014.

NASCIMENTO, P. T.; JUNIOR, W. G.; YU, A. S.; NIGRO, F. E. Suppliers involvement strategies in flex fuel vehicle development. Journal of Operations and Supply Chain Management, v. 5, n. 2, p. 2-12, 2012.

NASCIMENTO, P. T.; YU, A. S.; QUINELLO, R.; RUSSO, R.; NIGRO, F. Exogenous factors in the development of flexible fuel cars as a local dominant technology. Journal of Technology Management \& Innovation, v. 4, n. 4, p. 110-119, 2009.

NICHOLS, R. J. The metanol story: a sustainable fuel for the future. Journal of Scientific \& Industrial Research, v. 62, n. 1, p. 97-105, 2003.

OLIVA, F. L.; SOBRAL, M. C.; DAMASCENO, F.; TEIXEIRA, H. J.; GRISI, C. C. Risks and strategies in a Brazilian innovation - flexfuel technology. Journal of Manufacturing Technology Management, v. 25, n. 6, p. 916-930, 2014. 
PASCALE, R. T. The Honda effect. California Management Review, v. 38, n. 4, p. 80-91, 1996. PERA, M. Q. Injeção eletrônica: 20 anos de Brasil. All The Cars. 2008. Disponível em: $<$ https://allthecars. wordpress.com/2008/06/02/injecao-eletronica-20-anos-de-brasil/>. Acesso em: 12 ago. 2016.

POSSAS, M. L. Estruturas de mercado em oligopólios. São Paulo: Hucitec, 1990.

ROGERS, E. M.; OLAGUERA, N. S. Diffusion of innovations. 5. ed. Free Press, 2003.

RIZZI, C. A. Expansão das viagens de moto em São Paulo entre 1987 e 1997: aspectos econômicos e sociais. Revista Transporte y Territorio, n. 4, p. 118-132, 2011.

RUBIN, D. B. Causal inference using potential outcomes. Journal of the American Statistical Association, v. 100, n. 469, p. 322-331, 2005.

RUSSO, R. F. S. M.; SBRAGIA, R. Sensemaking na inovação: o caso da tecnologia flexfluel na indústria automotiva brasileira. In: SIMPÓSIO DE GESTÃO DA INOVAÇÃO TECNOLÓGICA, 16., 2010, Vitória. Anais... Vitória: Associação Nacional de Pós-Graduação e Pesquisa em Administração, 2010.

SAMANEZ, C. P.; FERREIRA, L. R.; NASCIMENTO, C. C. Avaliação da opção de troca de combustível no carro brasileiro flex: um estudo por região geográfica usando teoria de opções reais e simulação estocástica. Production, v. 24, n. 3, p. 628-643, 2014.

SERAPHIM, L. A. A motocicleta. Revista dos Transportes Públicos, ano 25, p. 209-218, 2003. SILVA, E. R.; CARDOSO, B. C.; SANTOS, M. P. O aumento da taxa de motorização de motocicletas no Brasil. Revista Brasileira de Administração Científica, v. 2, n. 2, p. 49-63, 2011. VAZZOLÉR, L. F.; BONACELLI, M. B.; CARNEIRO, A. M. O desenvolvimento de motores a álcool e bicombustível: concentração territorial e risco de perda das vantagens de first commer. Revista Economia \& Tecnologia, v. 8, n. 2, p. 157-166, 2012.

VASCONCELLOS, E. A. O custo social da motocicleta no Brasil. Revista dos Transportes Públicos, ano 30/31, p. 127-142, 2008.

VOLPATO, O.; THEUNISSEN, F.; COLLI, G.; LIU, X. Flex fuel engine management for small motorcycles. SAE Technical, 2008 (SAE Technical paper, 01-2729). Disponível em: <http://papers.sae.org/2007-01-2729/>.

WILLINGER, M. Designing economic experiments for evaluation purposes. Revista Brasileira de Inovação, v. 11, número especial, p. 219-238, 2012. 


\section{ANEXO I}

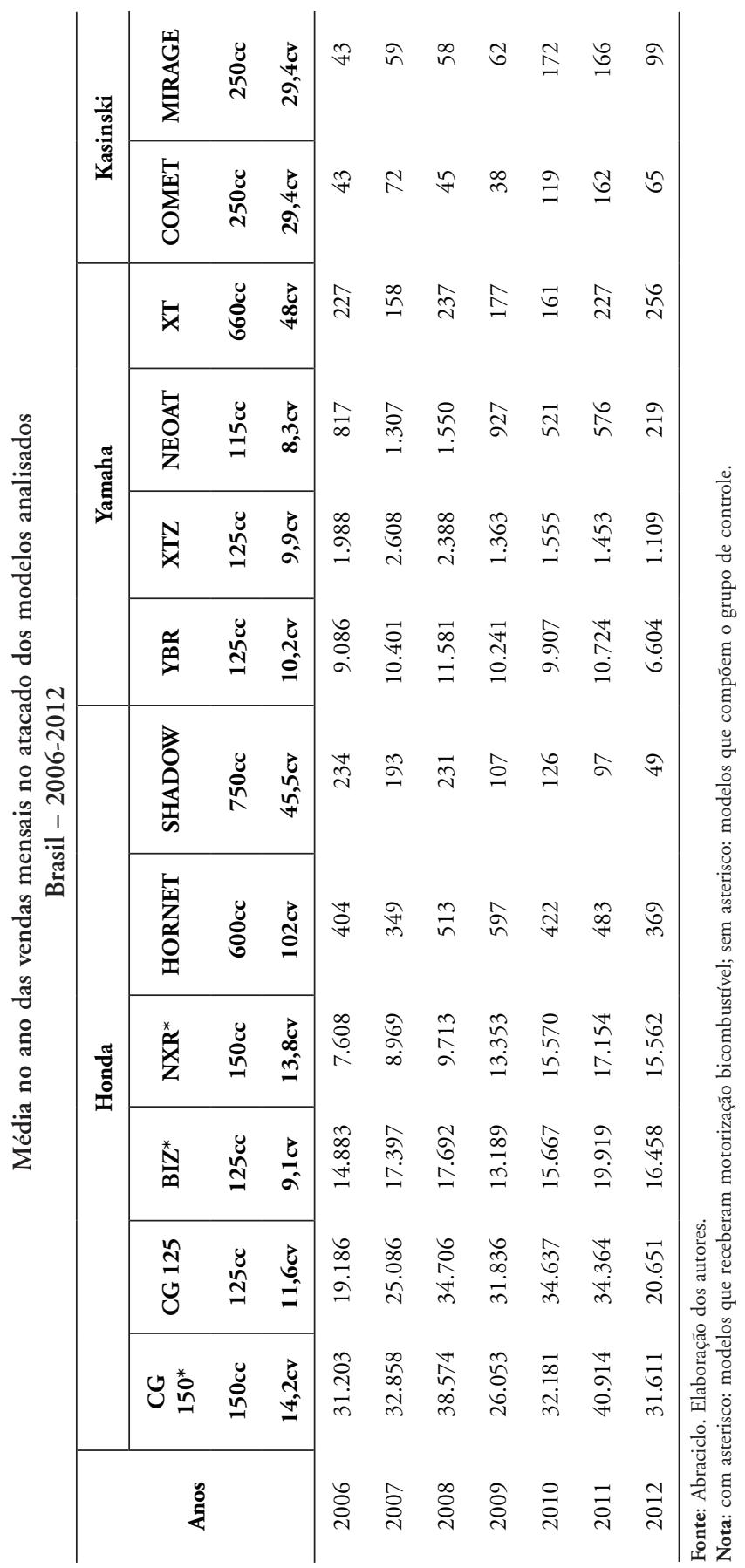




\section{APÊNDICE I - 0 modelo}

Considera-se a existência de $J+1$ modelos de motocicletas (unidades) à venda no Brasil. Supõe-se assim, sem perda de generalidade, que apenas o primeiro modelo é submetido à inovação tecnológica (intervenção ou tratamento) em determinada data, restando $J$ modelos como potenciais controles. Definem-se então $Y_{i t}^{N}$ como o valor observado ${ }^{22}$ para as vendas do modelo $i$ no tempo $t$ na ausência da intervenção, com $i=1, \ldots, J+1$ e $t=1, \ldots, T ; T_{0}$ como o número de períodos pré-intervenção, com $1 \leq T_{0}<T ;$; e, $Y_{i t}^{l}$ como o valor observado para unidade $i$ no tempo $t$ se a unidade $i$ sofrer a intervenção nos períodos $T_{0}+1$ a $T$.

Assume-se também que a intervenção não tem efeito sobre o resultado antes do período de sua implementação, ou seja, as vendas das motocicletas que sofreram intervenção não sofreram alterações em função da utilização do motor flex antes que ele fosse de fato instalado nos modelos. Dessa forma, para todo $t \in\left\{1, \ldots T_{0}\right\}$ e $i \in\{1, \ldots, J+1\}$, tem-se que $Y_{i t}^{I}=Y_{i t}^{N}$. Logo, considerando $\alpha_{i t}=Y_{i t}^{I}-Y_{i t}^{N}$ o efeito da intervenção para o modelo $i$ no tempo $t$, se a unidade $i$ tiver sido exposta à intervenção nos períodos $T_{0}+1, T_{0}+2, \ldots, T$ tem-se que: $Y_{i t}^{I}=Y_{i t}^{N}+\alpha_{i t}$.

Dessa forma, sendo $D_{i t}$ um indicador que recebe valor 1 se a unidade $i$ sofre intervenção no tempo $t$ e valor zero caso contrário, pode-se inferir que o resultado observado para unidade $i$ no tempo $t$ é $Y_{i t}=Y_{i t}^{N}+\alpha_{i t} D_{i t}$. Como apenas o primeiro modelo sofre a intervenção e somente após o período $T_{0}$, tem-se que:

$$
D_{i t}= \begin{cases}1 & \text { se } i=1 \text { e } t>T_{0}, \\ 0 & \text { caso contrário. }\end{cases}
$$

Assim, busca-se estimar $\left(\alpha_{1 T_{0}+1}, \ldots, \alpha_{1 T}\right)$, e para $t>T_{0}$ tem-se: $\alpha_{1 t}=Y_{1 t}^{I}-Y_{1 t}^{N}=$ $Y_{1 t}^{N}=Y_{1 t}-Y_{1 t}^{N}$. Como $Y_{1 t}^{I}$ é observado, para estimar $\alpha_{1 t}$ precisa-se apenas estimar $Y_{1 t}^{N}$. E sendo $Y_{1 t}^{N}$ determinado por um modelo de fatores é possível escrever:

$$
Y_{1 t}^{N}=\delta_{t}+\theta_{t} \mathrm{Z}_{i}+\lambda_{t} \mu_{i}+\varepsilon_{i t}
$$

em que $\delta_{t}$ representa um fator comum entre as unidades, que captura os efeitos da crise e das políticas macroeconômicas; $Z_{i}$ é um vetor de dimensão de covariadas observáveis, como, por exemplo, a cilindrada e a potência; $\theta_{t}$ e $\lambda_{t}$ são vetores $1 \times \mathrm{r}$ de parâmetros; $\mu_{i}$ é um vetor $\mathrm{r} \times 1$ de características não observáveis, tais 
como o efeito da marca e do design; e $\varepsilon_{i t}$ é o termo de erro, representando choques transitórios não observáveis ao nível de modelo com média zero para todo $i$. Como não há interesse em estimar a elasticidade preço da demanda, apenas a trajetória das vendas, adota-se um modelo reduzido.

Com todas as definições enunciadas até aqui, Abadie, Diamond e Hainmueller (2010) demonstram que existe um vetor $J \times 1$ de pesos $W=\left(w_{2}, \ldots, w_{J+1}\right)^{\prime}$, tal que $w_{J} \geq 0$ p para e $j=2, \ldots, J+1$ e $w_{2}+\cdots+w_{J+1}=1$, e que cada valor particular do vetor $W$ representa um potencial controle sintético, ou seja, uma média ponderada de vendas das unidades de controle que mimetiza as vendas da unidade tratada. Dessa forma, o valor da variável de resultado para cada controle sintético indexado por $W$ é:

$$
\sum_{j=2}^{J+1} w_{j} Y_{j t}=\delta_{t}+\theta_{t} \sum_{j=2}^{J+1} w_{j} Z_{j}+\lambda_{t} \sum_{j=2}^{J+1} w_{j} \mu_{j}+\sum_{j=2}^{J+1} w_{j} \varepsilon_{j t}
$$

Com base nisso, definido um vetor $\mathrm{K}=\left(k_{1}, \ldots, k_{T_{0}}\right)^{\prime}$ com tamanho $T_{0} \times 1$ como uma combinação linear de resultados pré-intervenção, tem-se $\bar{Y}_{i}^{K}=\sum_{s=1}^{T_{0}} k_{s} Y_{i s}$. Considerando, para simplificar, o caso $k_{1}=k_{2}=\cdots=k_{T_{0}}=1 / T_{0}$, o qual resulta em $\bar{Y}_{i}^{K}=T_{0}^{-1} \sum_{s=1}^{T_{0}} Y_{i s}$, tem-se uma simples média das variáveis de resultado para os períodos anteriores à intervenção.

Suponha então que se possa escolher $\left(w_{2}^{*}, \ldots, w_{J+1}^{*}\right)^{\prime}$ tal que:

$$
\sum_{j=2}^{J+1} w_{j}^{*} \bar{Y}_{j}^{K}=\bar{Y}_{1}^{K} \text { e } \sum_{j=2}^{J+1} w_{j}^{*} \mathrm{Z}_{j}=\mathrm{Z}_{1}
$$

Dessa forma, percebe-se que, se $\sum_{s=1}^{T_{0}} \lambda_{s} / T_{0} \neq 0$, então,

$$
Y_{1 t}^{N}-\sum_{j=2}^{J+1} w_{j}^{*} Y_{j t}=\frac{\lambda_{t}}{\sum_{s=1}^{T_{0}} \lambda_{s} / T_{0}} \sum_{j=2}^{J+1} w_{j}^{*} \frac{1}{T_{0}} \sum_{s=1}^{T_{0}}\left(\varepsilon_{j s}-\varepsilon_{1 s}\right)-\sum_{j=2}^{J+1} w_{j}^{*}\left(\varepsilon_{j t}-\varepsilon_{1 t}\right)
$$

Abadie, Diamond e Hainmueller (2010) mostram que a média do lado direito da equação (4) será próxima de zero se o número de períodos pré-intervenção for grande em relação à escala dos choques transitórios. Isso sugere que se pode utilizar, para $t \in\left\{T_{0}+1, \ldots T\right.$ :

$$
\widehat{\alpha}_{1 t}=Y_{1 t}-\sum_{j=2}^{J+1} w_{j}^{*} Y_{j t}
$$


como um estimador para $\alpha_{1 t}$. Uma vez que a equação (3) terá um valor exato apenas se $\left(\bar{Y}_{1}^{K}, Z_{1}\right)$ pertencer ao conjunto $\left.\left(\bar{Y}_{2}^{K}, Z_{2}\right), \ldots,\left(\bar{Y}_{J+1}^{K}, Z_{J+1}\right)\right\}$, e como isso dificilmente ocorre na prática, o modelo do controle sintético é selecionado tal que a equação (3) seja obtida de forma aproximada.

Na implementação do modelo, considera-se $\left.X_{1}=\left(Z_{1}^{\prime}, \bar{Y}_{1}^{K_{1}}, \ldots, \bar{Y}_{1}^{K_{M}}\right)^{\prime}\right]$ como um vetor $k \times 1$ de características pré-intervenção, ou seja, $X_{1}$ contém o valor dos preditores (cilindradas e potência) e das vendas do modelo exposto com $k=r+M$. De forma análoga, $k \times J$ é uma matriz que contém as mesmas variáveis para os modelos que não receberam o motor bicombustível, aqueles do grupo de doadores, em que a $j$-ésima coluna de $X_{0}$ é $\left(z_{j}^{\prime}, \bar{Y}_{j}^{K_{1}}, \ldots, \bar{Y}_{j}^{K_{M}}\right)^{\prime}$. O vetor de pesos ótimo $W^{*}$ é então selecionado de forma a minimizar a distância, $\left\|X_{1}-X_{0} W\right\|$, entre $X_{1} \mathrm{e} X_{0} W$, sujeito às restriçōes $w_{2} \geq 0, \ldots, w_{J+1} \geq 0 \mathrm{e} w_{2}+, \ldots, w_{J+1}=1$. Em particular, considera-se $\left\|X_{1}-X_{0} W\right\|_{V}=\sqrt{\left(X_{1}-X_{0} W\right)^{\prime} V\left(X_{1}-X_{0} W\right)}$, em que $V$ é uma matriz simétrica positiva semidefinida $k \times k$, que atribui pesos às covariadas de acordo com seu poder preditivo sobre o resultado. 


\section{APÊNDICE II - Testes de validação cruzada dos controles sintéticos estimados}

Os Gráficos A1, A2 e A3 ilustram os “testes de validação cruzada”, isto é, novos sintéticos dados pela exclusão de uma unidade do grupo de controle a cada estimativa. As séries originais dos índices das vendas (linhas espessas) aparecem nos gráficos para que sejam comparadas. Por inspeção visual, nota-se que todos sintéticos seguem o mesmo traçado. Portanto, infere-se que os resultados apresentados possuem um bom grau de ajuste. As trajetórias que mais se diferenciam da original são aquelas em que as motocicletas que receberam grande peso no grupo de doadores são retiradas - o efeito gerado pela ausência dessas motocicletas dentro do grupo de controle mostra a importância desses modelos para a estimação dos controles sintéticos.

\section{GRÁFICO A1 - CG 150}

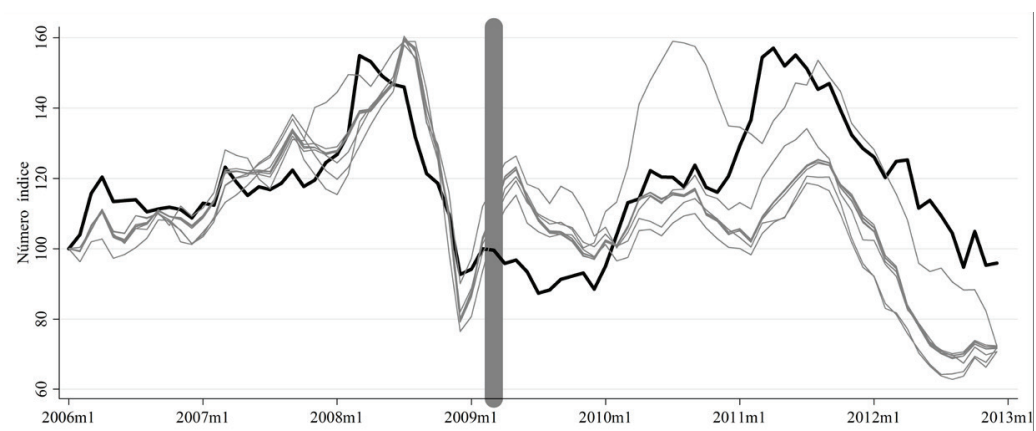

GRÁFICO A2 - BIZ 125

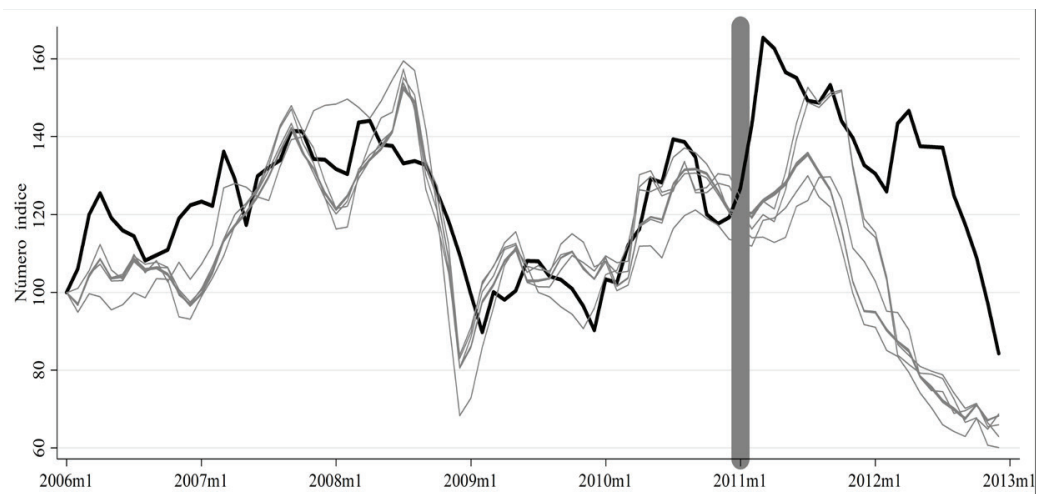




\section{GRÁFICO A3 - NXR 150}

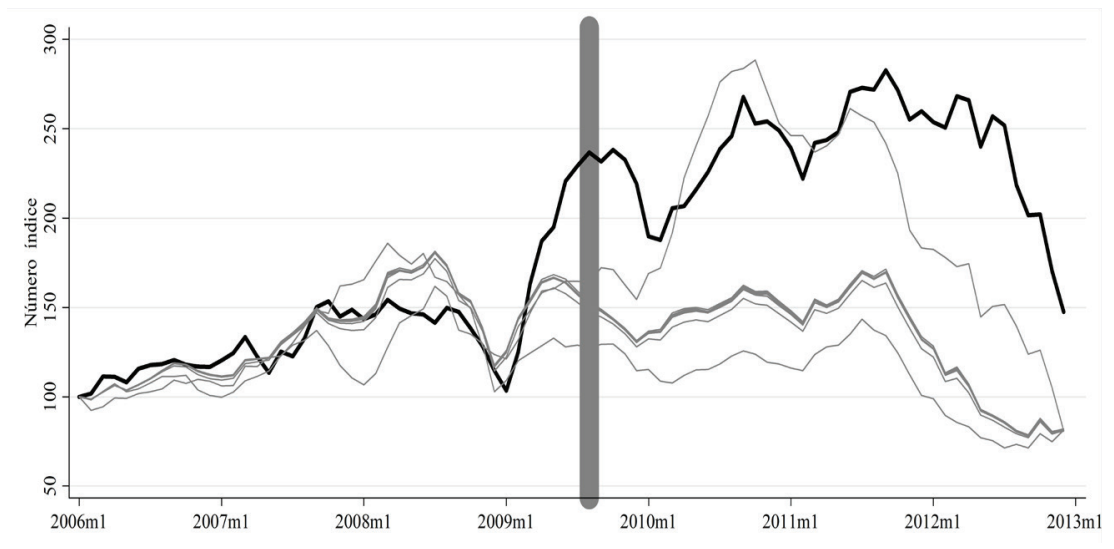

